\title{
Preface
}

\section{4th International Conference on New Frontiers in Physics 2015}

The conference series "New Frontiers in Physics" aims to promote scientific exchange and development of novel ideas in science with particular emphasis on interdisciplinarity. The main topics of the conference are high energy particle and nuclear physics, heavy ion physics, quantum optics and quantum entanglement, cosmology, astrophysics, gravity, mathematical physics.

The 4th International Conference on New Frontiers in Physics (ICNFP 2015) attracted about 200 participants. At the opening of the Conference Dr Konstantinos Zormpas, the General Director of the Academy which hosted the conference, welcomed the participants. During the conference 6 lectures, 81 plenary and 93 parallel talks as well as 23 posters were presented. Altogether during ICNFP 2015 there were given 203 oral or poster presentations. A special session devoted to the 50th anniversary of Hagedorn's Temperature and the Statistical Bootstrap Model has been organized on the 26th of August, with an introductory opening talk by Prof. Jan Rafelski.

A science exhibition and outreach day has been organized in the Sailing Club of Chania on the 28th August, with Opera singing by the Soprano Kalliopi Petrou and a

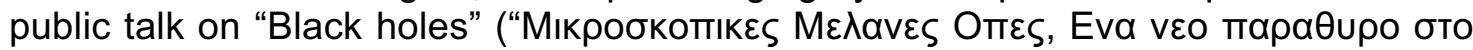
$\Sigma$ ऽитаv") by Prof. Ilias Kyritsis in Greek language in the evening. In addition, there was a Public talk in English language with title "The Old One does not throw dice, Einstein's dialog with God" by Prof. Thomas Naumann, visit to the "Park for the Preservation of Flora \& Fauna", an Opera Gala (Kalliopi Petrou (soprano), Alessia Toffanin (piano)), classical music concert by Svetlana Nor (violin), Vladimir Nor (Cello) and Ruben Muradyan (piano), as well as excursions and a conference dinner with traditional Cretan Music. The "History of Crete" was presented by Emanuela Larentzakis as an after dinner talk.

We would like to thank all the conference participants as well as the members of the International Advisory Committee, the Local Organizing Committee, the Organizing Institutes and Sponsors, the Technical University of Chania, the University of Crete at Herakleion, Christina Kourkoumelis from University of Athens, the "Go-lab European Outreach project" and the Chania Sailing Club for the organization of public events and outreach, and especially the hosting Orthodox Academy of Crete for the extremely warm atmosphere of the conference. We would also like to thank Nikolay Gulitsky and Andrey Seryakov from Saint-Petersburg State University for the photos in the preface and the conference webpage and Vladimir Kovalenko from SaintPetersburg State University and the staff of "European Physical Journal Web of Conferences" for the help with publishing the proceedings.

\section{Larissa Bravina, Yiota Foka and Sonia Kabana,}



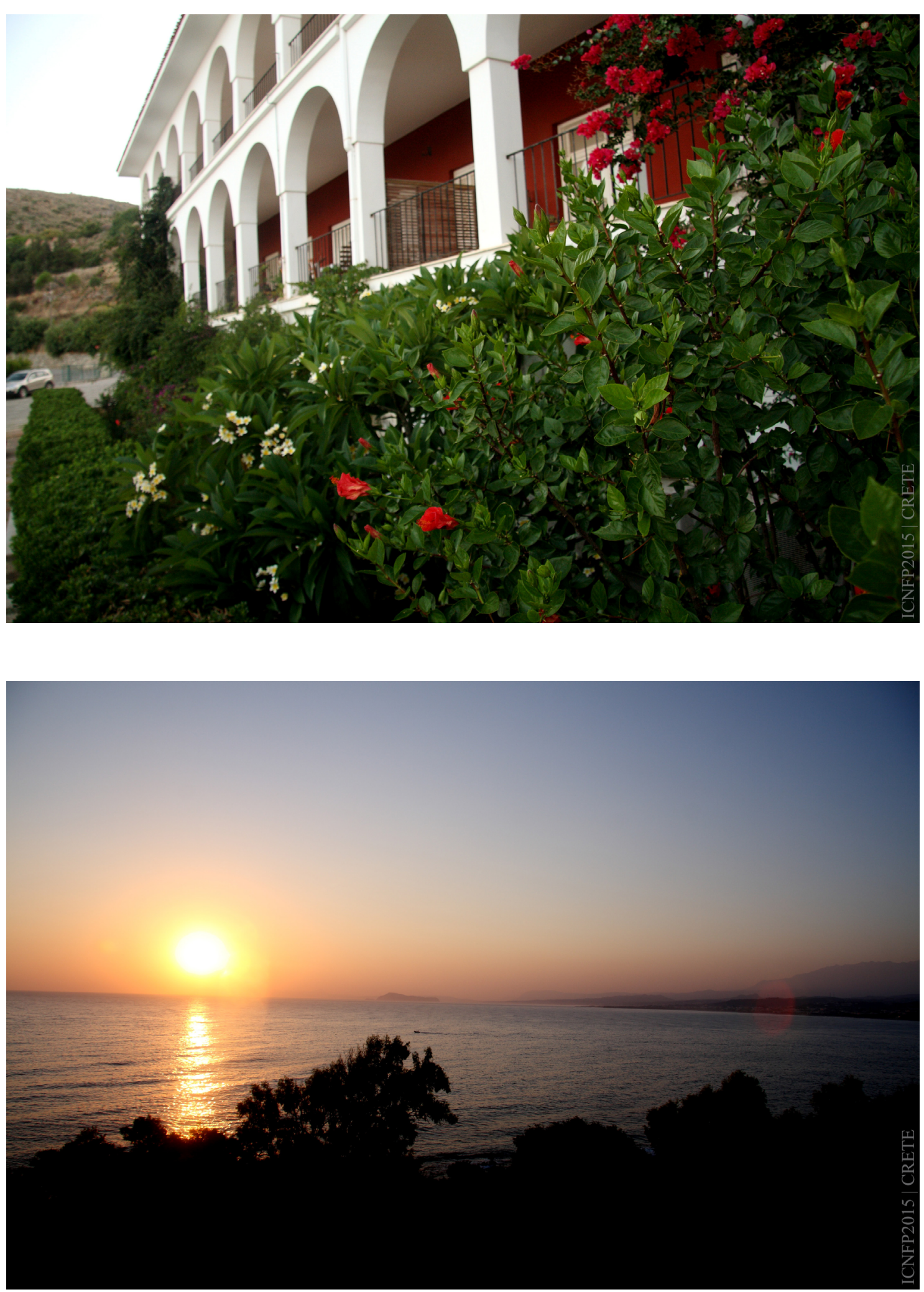

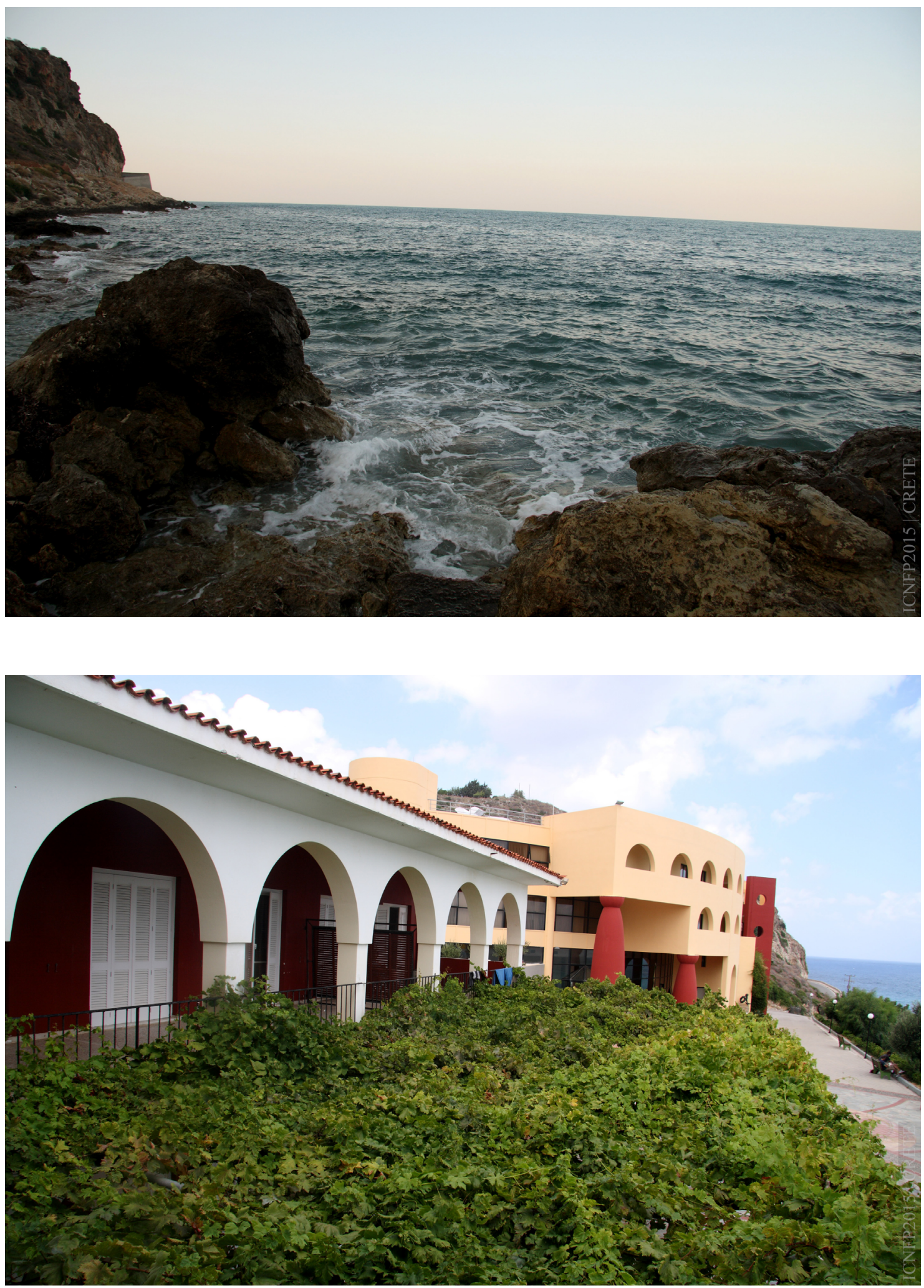


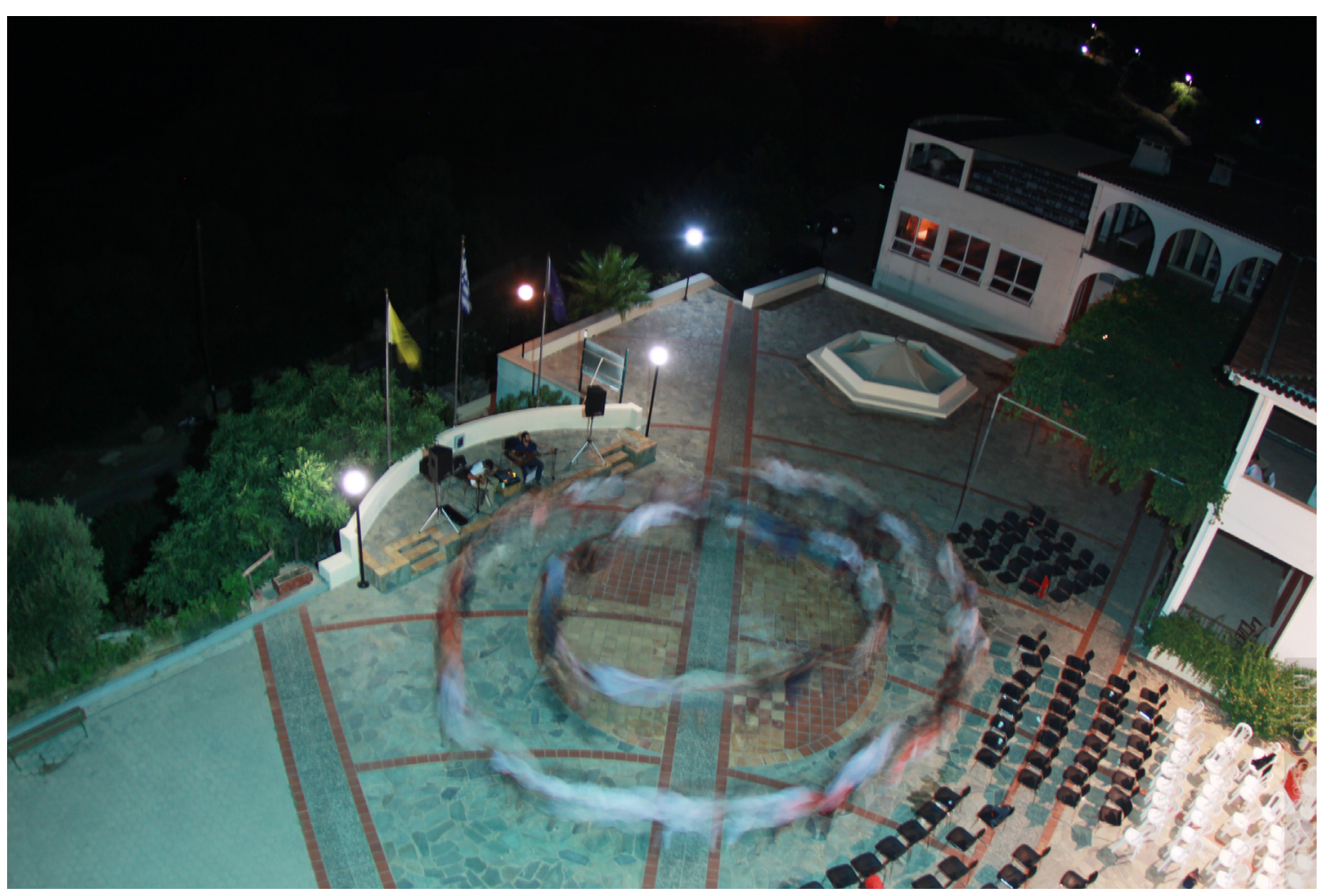

